\title{
Polimorfismo do gene do receptor de proģesterona (PROGINS) em mulheres com câncer de mama. Estudo caso-controle
}

\author{
Polymorphism in genes of the progesterone receptor (PROGINS) in women with breast cancer. A \\ case-control study
}

José Juvenal Linhares ${ }^{1}$, Ismael Dale Cotrim Guerreiro da Silva², Naiara Correa Nogueira de Souza ${ }^{3}$, Emmanuelle Coelho Noronha ${ }^{4}$, Odair Ferraro ${ }^{5}$, Fausto Farah Baracat ${ }^{6}$

\section{RESUM0}

Objetivos: analisar a correlação entre o polimorfismo PROGINS e o câncer de mama. Métodos: estudo caso-controle desenvolvido entre abril e outubro de 2004 com o pareamento de 50 mulheres com diagnóstico histopatológico de carcinoma de mama e 49 mulheres saudáveis. A inserção Alu de 306 pares de base no intron G do gene do receptor da progesterona denominada PROGINS foi detectada por meio de reação em cadeia da polimerase e analisada em gel de agarose $2 \%$ corado com brometo de etídio. Os grupos controle e experimental foram comparados, por meio de programa estatístico Epi-Info 6.0, quanto aos genótipos e às freqüências alélicas, utilizando-se o teste do $\chi^{2}$. Resultados: em relação ao PROGINS encontramos uma prevalência na população estudada de 62 (62,6\%) indivíduos homozigotos selvagens, 35 (35,3\%) de heterozigotos e dois $(2,1 \%)$ casos com a presença da mutação. Não foi evidenciada diferença significante em relação ao polimorfismo PROGINS, quando comparados os casos e controles, seja com relação à homozigose (62 vs 65,3\%), heterozigose (36 vs $34,6 \%$ ) ou à presença de mutação (2,0 vs 2,1\%), com p de $0,920(\mathrm{OR}=1,01), 0,891(\mathrm{OR}=1,06)$ e $0,988(\mathrm{OR}=1,10)$, respectivamente. Conclusões: os resultados mostraram que o polimorfismo PROGINS não conferiu risco substancial de câncer de mama em seus portadores.

PALAVRAS-CHAVE: Neoplasias mamárias; Polimorfismo (Genética); Receptores de progesterona

\section{ABSTRACT}

Purpose: to analyze the correlation between PROGINS polymorphism and breast cancer. Methods: a case-control study was carried out from April to October 2004. The genotypes of 50 women with breast cancer and 49 healthy women were analyzed. The 306-base pair Alu insertion polymorphism in the G intron of progesterone receptor gene was detected by polymerase chain reaction and analyzed on $2 \%$ agarose gel stained with ethidium bromide. The control and experimental groups were compared regarding genotypes using the statistical Epi-Info 6.0 program and for frequencies the exact Fisher test or $\chi^{2}$ test were used. p value smaller p than 5\% was considered to be significant. Results: in relation to PROGINS we found in the studied population a prevalence of 62 (62.6\%) wild homozygous, 35 (35.3\%) heterozygous individuals and two (2.1\%) cases with the presence of the mutation. Regarding PROGINS polymorphism, significance was not evidenced when cases and controls were compared, as related to homozygosis (62 vs 65.3\%), heterozygosis (36 vs 34,6\%) or the mutation ( 2.0 vs $2.1 \%$ ), with $\mathrm{p}=0.920(\mathrm{OR}=1.01), 0.891(\mathrm{OR}=1.06)$, and $0.988(\mathrm{OR}=1.10)$, respectively. Conclusions: the results show that single-gene PROGINS polymorphism does not confer a substantial risk of breast cancer to its carriers.

KEYWORDS: Breast neoplasms; Polymorphism (Genetics); Receptors, progesterone

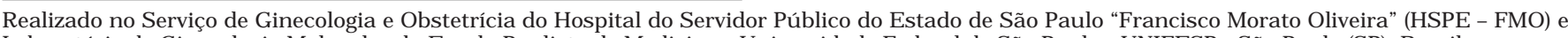
Laboratório de Ginecologia Molecular da Escola Paulista de Medicina - Universidade Federal de São Paulo - UNIFESP - São Paulo (SP), Brasil.

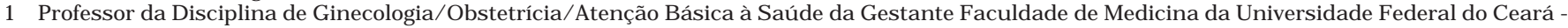
UFC - Fortaleza (CE), Brasil.

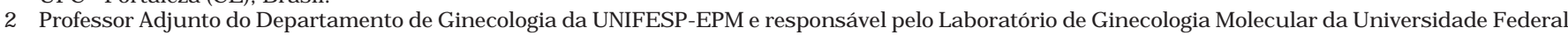
de São Paulo - UNIFESP - São Paulo (SP), Brasil.

3 Doutoranda do Departamento de Ginecologia da Universidade Federal de São Paulo - UNIFESP - São Paulo (SP), Brasil.

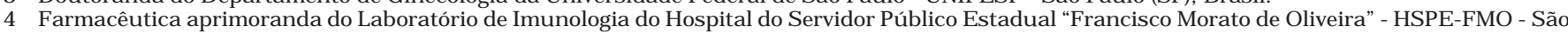
Paulo (SP), Brasil.

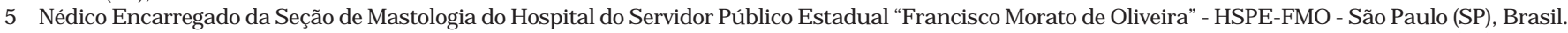

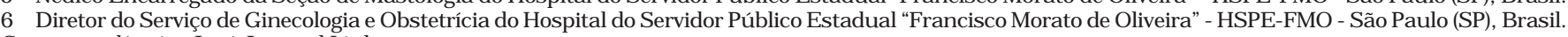
Correspondência: José Juvenal Linhares

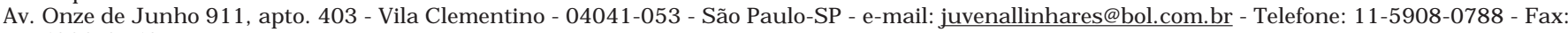
11-5088-8153 


\section{Introdução}

No Brasil, o câncer de mama é o mais freqüente em incidência e mortalidade no sexo feminino, apresentando curva ascendente a partir dos 25 anos de idade e concentrando a maioria dos casos entre os 45 e 50 anos. Representa, aproximadamente, $20 \%$ do total de casos diagnosticados e $15 \%$, em média, das mortes por câncer no Brasil. É mais comum em mulheres de classe social elevada e entre aquelas que vivem em grandes cidades ${ }^{1}$. Isto sugere que fatores ambientais, estilo de vida e alimentação interferem na gênese do câncer de mama.

Estima-se que aproximadamente 10\% das mulheres da população geral dos países ocidentais desenvolverão, em alguma época da vida, o câncer de mama. Esta estimativa poderá diminuir em algumas subpopulações, como as das mulheres negras, ou aumentar, como as das mulheres judias de origem asquenaze ${ }^{2}$.

Muitos fatores vêm sendo identificados como relacionados com o câncer de mama, além do grupo racial, faixa etária e fatores reprodutivos. Este conjunto multifatorial caracteriza a complexa etiopatogenia desta neoplasia ${ }^{3}$. Uma pequena proporção dos casos de câncer de mama pode ser atribuída a razões puramente genéticas, sugerindo a participação associada de outros fatores: dieta, alcoolismo e exposição a carcinógenos.

As novas tecnologias em genética molecular estão trazendo para esta área de estudo verdadeira revolução no conhecimento dos mecanismos etiológicos, bem como também na conduta terapêutica, abrindo perspectivas para a descoberta de medidas de prevenção no futuro. A principal destas inovações foi a descoberta de vários sítios de mutações nos genes BRCA1 e BRCA2 e a detecção destes entre pacientes afetados e não afetados de famílias com segregação de câncer de mama ${ }^{3}$.

Há cerca de trinta anos, a suscetibilidade ao câncer era principalmente atribuída aos níveis de exposição aos carcinógenos. Atualmente, embora essa correlação seja efetiva, é evidente a existência de inúmeros fatores biológicos responsáveis pela variabilidade individual, os quais se apresentam relevantes em várias doenças ${ }^{4}$.

Pelo estudo da suscetibilidade individual ou de subpopulações, por meio da determinação das freqüências dos polimorfismos que caracterizam diferentes capacidades de metabolização, será possivel identificar fatores de risco para muitas doenças e também compreender os mecanismos pelos quais elas se desenvolvem. Essa metodologia poderá auxiliar o indivíduo a optar por um estilo de vida ou tipo e local de trabalho mais saudável e deverá contribuir com a clínica médica na prescrição de drogas ${ }^{4}$.

O receptor da progesterona $(\mathrm{RP})$ faz parte da superfamília dos receptores esteróides derivados do ácido retinóico. O gene para esse receptor encontra-se localizado no cromossomo 11q22-23. O RP é importante regulador do crescimento da glândula mamária e do aparelho reprodutor feminino, e encontra-se envolvido na gênese de tumores malignos $^{5}$. Esse receptor possui duas isoformas: a isoforma " $A$ " é capaz de inibir o gene de ativação dos receptores estrogênicos, ao passo que a isoforma "B" tem a capacidade de ativá- $10^{6}$.

O PROGINS acontece devido a processo de inserção gênica. Esse se deve a presença do elemento Alu. O elemento Alu dentro do genoma humano é aquele com maior poder de mobilidade, existindo aproximadamente 1.200 .000 cópias desse elemento. Cada repetição do Alu tem aproximadamente 300 nucleotídeos em seu comprimento. Sua mobilidade ocorre via processo de retroposição que envolve transcrição reversa da RNA polimerase III primária para a forma de cDNA, acompanhada da sua integração ao genoma ${ }^{7}$.

A inserção do elemento móvel Alu no intron G do RP leva à substituição do G para T no éxon 4, causando a troca da valina pela leucina no ponto principal do RP. Semelhante substituição da citosina pela timina no éxon 5 também já foi reportada com a inserção do elemento Alu. A esse complexo polimorfismo genético funcional denominou-se PROGINS ${ }^{7}$.

As ações biológicas da progesterona são mediadas por duas isoformas de seu receptor, respectivamente "A" e "B". Em seres humanos os dois RNA transcritos são gerados a partir de um único gene que tem, porém, regiões promotoras diferentes. Estruturalmente, as proteínas diferem apenas quanto à presença de 164 aminoácidos na região $\mathrm{N}$-terminal do receptor " $\mathrm{B}$ "6.

A isoforma "A" do RP é a proteína envolvida com o PROGINS; esse polimorfismo levará a um decréscimo de sua estabilidade, fazendo com que esta perca a sua capacidade de inibir a ativação dos receptores estrogênicos, causando inadequado controle desses receptores, expondo dessa forma, a glândula mamária a maior exposição estrogênica ${ }^{6}$. Acredita-se que a isoforma " $A$ ", sob ação do polimorfismo, levaria, também, a uma maior expressão da isoforma "B" (responsável pela ativação dos receptores estrogênicos), contribuindo para aumento da ação oncogênica do PROGINS ${ }^{8}$.

A presença do PROGINS na população germânica foi relacionada com risco significante de câncer de mama ${ }^{8}$. Estudo com polimorfismo 
funcional do RP verificou acréscimo no risco de câncer de mama ao estudar 990 casos, comparados com 1.364 controles $^{9}$. Estudo com 187 irlandesas com câncer de mama constataram significativa associação do PROGINS com o risco de câncer de mama ${ }^{10}$. Estudos com mulheres germânicas em idade inferior a 51 anos, caucasianas da Carolina do Norte e mulheres do sul da Inglaterra relataram relação inversa entre o PROGINS e o risco de câncer de mama ${ }^{5,11,12}$.

Em vista dos relatos conflitantes de alguns estudos publicados e da escassez de estudos nacionais sobre esse assunto, propusemos avaliar a correlação entre os polimorfismos em genes responsáveis pela ação dos esteróides sexuais (PROGINS) e o carcinoma de mama.

\section{Pacientes e Métodos}

No período de abril a outubro de 2004 foram colhidas amostras de sangue periférico de 50 mulheres portadoras de carcinoma ductal invasivo de mama, independentemente do estádio clínico e de tratamentos anteriores, atendidas no ambulatório de Mastologia do Hospital do Servidor Público Estadual de São Paulo "Francisco Morato Oliveira". Os critérios de inclusão foram: suspeita clínica e/ou radiológica de câncer de mama, com confirmação histopatológica da peça cirúrgica. Foram excluídas as pacientes com não confirmação do diagnóstico pelo exame anatomopatológico, qualquer outro tipo de carcinoma de mama, que não o ductal invasivo, e as usuárias de terapia hormonal (12 pacientes excluídas).

Precedendo a consulta ambulatorial foram colhidos $5 \mathrm{~mL}$ de sangue venoso (veia periférica) em tubos Vacutainer ${ }^{\circledR}$ com EDTA. No mesmo período foram colhidas amostras de raspado bucal de 49 mulheres sem câncer de mama (grupo controle). Nesse grupo, optou-se por esse tipo de metodologia devido à resistência dos controles em colher amostra de sangue periférico e à possibilidade de obtenção das informações com esta tecnologia. Os critérios de inclusão foram: ausência de câncer de mama ou da suspeita deste, por avaliação clínica e/ou radiológica. Foram excluídas as mulheres com diagnóstico ou suspeita clínica e/ou radiológica de câncer de mama (alterações mamográficas Bi-rads ${ }^{\circledR}$ 3,4 ou 5), antecedentes de cirurgia mamária prévia, portadoras de qualquer doença mamária, seja benigna ou maligna, e usuárias de terapia hormonal ( 14 controles excluídos).

As pacientes do grupo controle foram selecionadas no ambulatório de climatério e de uroginecologia do mesmo hospital. No grupo controle, também foram excluídas as usuárias de TH, portadoras de qualquer doença mamária seja benigna ou maligna e todas aquelas com alterações mamográficas Bi-rads ${ }^{\circledast} 3,4$ ou 5 . O material foi colhido precedendo a consulta ambulatorial após escovado de mucosa bucal com escova do tipo Cytobrush ${ }^{\circledR}$, sendo o material armazenado em tubos secos.

Os dois grupos da amostra foram pareados, não se observando diferenças quanto às características epidemiológicas, sendo estas descritas na Tabela 1.

Tabela 1 - Comparação entre os antecedentes e os dados epidemiológicos das pacientes em estudo e o grupo controle.

\begin{tabular}{lccc}
\hline Parâmetros & Casos & Controles & Valores de $p$ \\
\hline Idade & $54,7 \pm 13,5$ & $50,5 \pm 10,3$ & $p=0,953$ \\
Raça negra & $13,0(26 \%)$ & $8,0(16,4 \%)$ & $p=0,799$ \\
Idade da menarca & $13,0 \pm 1,7$ & $13,2 \pm 2,3$ & $p=0,861$ \\
Menarca <12 anos & 15,0 & 16,0 & $p=0,841$ \\
Status menopausal & $25,0(50 \%)$ & $25,0(51 \%)$ & $p=0,908$ \\
Primeiro parto & 23,2 & 24,5 & $p=0,905$ \\
Número de gestações & $2,7 \pm 2,3$ & $2,8 \pm 2,4$ & $p=0,500$ \\
Nuliparidade & 7,0 & 7,0 & $p=0,867$ \\
História familiar & $5,0(10 \%)$ & $4,0(8,2 \%)$ & $p=0,953$ \\
Tabagismo & $9,0(18 \%)$ & $14,0(28,5 \%)$ & $p=0.452$ \\
\hline
\end{tabular}

0 valor de $p$ foi baseado no test do $\chi^{2}$, sendo considerado significante quando menor que $5 \%$.

A colheita do sangue e do raspado bucal foram realizadas após a assinatura de termo de consentimento pelas envolvidas no estudo. O presente estudo foi analisado e aprovado pelo Comitê de Ética em Pesquisa da Universidade Federal de São Paulo/Hospital São Paulo e pela Comissão de Ética em Pesquisa do HSPE - FMO, e todas as pacientes incluídas no protocolo assinaram termo de consentimento livre e esclarecido. Utilizou-se de formulário padronizado para a coleta dos dados, os quais foram posteriormente transferidos para planilha eletrônica (Excel - Microsoft Office 2000).

As amostras de sangue foram colhidas por

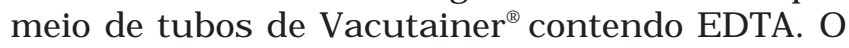
sangue total foi centrifugado a $1.000 \mathrm{rpm}$ por 10 minutos, separando-se em seguida o plasma e as hemácias (esses foram desprezados por não interessar ao estudo) dos leucócitos (células que foram utilizadas no estudo). As amostras de raspado bucal foram obtidas por meio de escova do tipo Cytobrush $^{\circledR}$ friccionadas contra a mucosa de revestimento bucal seguido de bochecho com soro fisiológico $0,9 \%$ e colocadas em tubo seco. As amostras citológicas, leucócitos e células bucais, assim obtidas, foram conservadas em $-80^{\circ} \mathrm{C}$ até posterior extração de DNA genômico. 
A extração do DNA foi realizada segundo protocolo do Kit GFX ${ }^{\circledR}$ da Amersham-Pharmacia ${ }^{\circledR}$ para células bucais e sangüíneas. Resumidamente, o material celular obtido das células sanguíneas (leucócitos) ou de esfregaço bucal foi inicialmente centrifugado, desprezando-se o excesso de sobrenadante. Ao pellet celular adicionaram-se 500 $\mu \mathrm{L}$ de solução de extração, agitando-se até que todo o pellet estivesse dissolvido. Essa etapa é seguida de centrifugação a $14.000 \mathrm{rpm} / 1$ minuto com o objetivo de separar restos celulares do sobrenadante, que será nesse momento colocado na coluna de filtragem. Após nova centrifugação a $8.000 \mathrm{rpm} / 1$ minuto, uma nova alíquota de $500 \mu \mathrm{L}$ de solução de extração foi colocada na coluna, com posterior centrifugação a $8.000 \mathrm{rpm} / 1$ minuto.

Seguiu-se então, a colocação de $500 \mu \mathrm{L}$ de solução de lavagem com nova centrifugação a $14.000 \mathrm{rpm} / 3$ minutos. Nesse momento adicionaram-se à coluna $70 \mu \mathrm{L}$ de água milliQ autoclavada pré-aquecida a $70^{\circ} \mathrm{C}$, seguindo-se a centrifugação a $14.000 \mathrm{rpm} / 1$ minuto, coletando-se o eluído em tubo do tipo Eppendorf ${ }^{\circledR}$. O DNA assim obtido está pronto para ser utilizado em PCR.

Para análise dos polimorfismos presentes no gene de receptor de progesterona (PROGINS) utilizamos a técnica de PCR. Resumidamente, as amplificações foram realizadas em volume de $25 \mathrm{~mL}$ sob condições padrões para PCR (Master Mix ${ }^{\circledR}$ ). As condições de ciclagem foram as seguintes: desnaturação inicial a $94^{\circ} \mathrm{C}$ por 5 min e 35 ciclos de desnaturação a $94^{\circ} \mathrm{C}$ por $1 \mathrm{~min}$, anelamento a $55^{\circ} \mathrm{C}$ por $1 \mathrm{~min}$, polimerização a $72^{\circ} \mathrm{C}$ por 1 min até extensão final a $72^{\circ} \mathrm{C}$ por $7 \mathrm{~min}$. As seguintes seqüências de oligonucleotídeos iniciadores foram utilizadas para a amplificação da região que contém o polimorfismo PROGINS no intron $G$ do gene do receptor de progesterona: 5'-GGC AGA AAG CAAAAT AAAAAG A3' (primer 5') e 5'-AAA GTA TTT TCT TGC TAA ATG TC-3' (primer 3'). Podemos observar na leitura do PCR três opções distintas: a presença de duas bandas com 149 pares de base (bp) é considerada como homozigota selvagem (não apresenta a mutação), a presença de uma banda com 149 bp e outra com 455 bp caracteriza a heterozigose para o PROGINS (presença da inserção em apenas uma fita de DNA, não apresenta mutação). As amostras nessas duas situações são consideradas negativas. A presença das duas bandas com 455 bp caracteriza a amostra como positiva para a presença da inserção gênica nas duas fitas do DNA (mutada), como observadas na Figura 1. O estudo do PROGINS foi realizado pela técnica de ampliação por PCR e leitura em gel de agarose a $2 \%$ corado com brometo de etídio GeneGel Excel 12.5/24 (Amersham Pharmacia Biotech $^{\circledR}$ ) em aparelho GenePhor (Amershan Pharmacia ${ }^{\circledR}$ ).

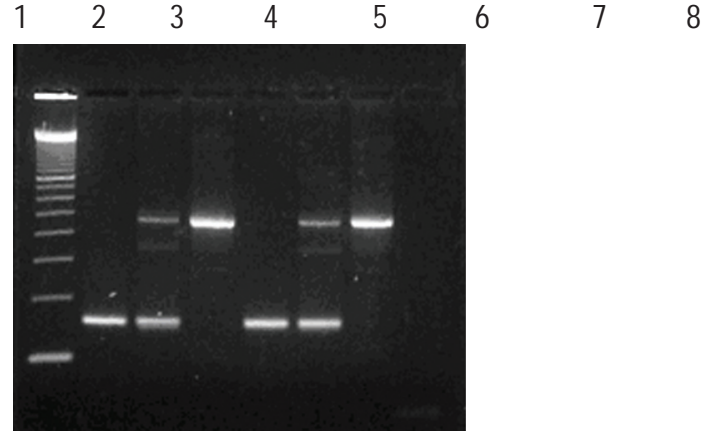

Figura 1 - Leitura da PCR para o PROGINS em gel de agarose a $2 \%$ corado pelo brometo de etídio, contendo os possíveis genótipos para o polimorfismo PROGINS. Linha 1 - Marcador de peso molecular 100 bp; linhas 2 e 5 - amostras homozigotas selvagem para o PROGINS (149 bp); linhas 3 e 6 - amostras heterozigotas para o PROGINS (149 bp e 455B bp[= 149 bp + inserção Alu de 306 bp]); linhas 4 e 7 - amostras mutadas para o PROGINS (455 bp); linha 8 - controle negativo.

Os grupos controle e experimental foram comparados, com o uso de programa estatístico EpiInfo 6.0, quanto aos genótipos e às freqüências alélicas utilizando-se o teste de $\chi^{2}$. O valor de $\mathrm{p}$ menor que $5 \%$ foi considerado significante.

\section{Resultados}

Em relação ao PROGINS, encontramos uma prevalência na amostra estudada (casos e controles) de $62(62,6 \%)$ indivíduos homozigotos selvagens, $35(35,3 \%)$ de heterozigotos e dois $(2,1 \%)$ casos com a presença da mutação (Tabela 2).

No grupo com câncer de mama, observamos a freqüência dos genótipos para o polimorfismo PROGINS de 31 pacientes homozigotos selvagens (62\%), 18 heterozigotos (36\%) e apenas um caso mutado (2\%) (com a presença da inserção Alu nas duas fitas de DNA). Nos controles, evidenciamos 31 mulheres homozigotas selvagens (65,3\%), 17 heterozigotas $(34,6 \%)$ e um $(2,1 \%)$ caso com a inserção nas duas fitas do DNA.

Tabela 2 - Freqüências genotípicas para o polimorfismo PROGINS na população estudada (casos + controles) e em mulheres com e sem carcinoma de mama.

\begin{tabular}{lcccc}
\hline & $\begin{array}{c}\text { Casos }+ \\
\text { Controles }\end{array}$ & Casos & Controles & $\begin{array}{c}\text { Valores de } \\
\text { p e OR }\end{array}$ \\
\hline Homozigotos & $62(62,6 \%)$ & $31(62,0 \%)$ & $31(65,3 \%)$ & $p=0,920$ \\
& & & & OR $=1,01$ \\
Heterozigotos & $35(35,3 \%)$ & $18(36,0 \%)$ & $17(34,6 \%)$ & $p=0,891$ \\
& & & & OR $=1,06$ \\
Mutados & $2(2,1 \%)$ & $1(2,0 \%)$ & $1(2,1 \%)$ & $p=0,988$ \\
& & & & $\mathrm{OR}=1,10$
\end{tabular}

0 valor de $\mathrm{p}$ foi baseado no test do $\chi^{2}$, sendo considerado significante quando menor que 5\%. OR: "odds ratio"; IC 95\% (intervalo de confiança). 
Não foi evidenciada diferença estatística em relação ao PROGINS, quando comparados casos e controles, seja com relação à homozigose, heterozigose ou à mutação, com p de 0,920, 0,891 e 0,988 , respectivamente (Tabela 2 ).

\section{Discussão}

Vários genes devem estar envolvidos com a etiopatogenia do câncer de mama, e estudos vêm sendo realizados, como o polimorfismo da classe das enzimas glutationa S-transferase, p53, dentre outros, com o intuito de rastrear grupos de maior suscetibilidade e procurar por meio deles individualizar a prevenção e a terapêutica ${ }^{13}$.

A etiopatogenia do câncer mamário é multifatorial, o que dificulta a seleção de grupo de mulheres com maior risco. A progesterona parece estar envolvida na gênese do câncer de mama, mediante regulação das metaloproteinases de matriz extracelular, estimulando os fatores inibidores destas enzimas. Age também sobre a expressão de fatores angiogênicos e sobre os fatores que regulam o ciclo celular. Também atua por meio da estimulação de fatores de crescimento epidérmico (EGF) e citocinas que contribuem diretamente para a carcinogênese mamária ${ }^{14,15}$.

A influência desse polimorfismo sobre o RP já foi determinada em outras doenças estrogêniodependentes como endometriose ${ }^{14}$, câncer de endométrio $^{16}$ e câncer de ovário ${ }^{17}$.

O conhecimento das propriedades carcinogenéticas da progesterona em células mamárias e a ausência de estudos com a população brasileira incentivaram-nos a procurar correlação entre o polimorfismo PROGINS e o risco para câncer de mama, na tentativa de encontrar um marcador que pudesse auxiliar na prevenção primária da doença.

Encontramos na população em estudo (casos e controles) baixa prevalência da inserção PROGINS de $2,1 \%$, o que talvez possa ser atribuído ao fato de a inserção do elemento Alu ter sido incorporada ao genoma humano recentemente . $^{4}$

Em estudos do tipo caso-controle, encontrouse risco significante de câncer de mama, o que não está de acordo com nossos resultados ${ }^{8,9}$. Uma das razões para essa divergência pode ser a importante mistura racial da população brasileira. Conseqüentemente, cuidado deve ser tomado ao analisar dados de diferentes populações, sendo necessária a comparação com outros estudos nacionais.

Os resultados não evidenciaram associação do PROGINS com câncer de mama, seja com rela- ção à homozigose, heterozigose ou à mutação. Esses resultados se superpõem a outros estudos com metodologias semelhantes (caso-controle pareado), porém com número maior de pacientes (superior a 100 pacientes com câncer de mama) $)^{5,11,12,18}$. O pequeno número de pacientes da amostra limita o estudo na avaliação da real prevalência deste polimorfismo nas mulheres brasileiras e na correlação deste com o câncer de mama.

A limitação do número de casos em 50 pacientes deveu-se aos resultados muito semelhantes nos dois grupos da amostra com p próximo de 1,00 , o que não nos incentivou a prosseguir a investigação.

Em conclusão, os dados do nosso estudo não nos permitiram associar o polimorfismo PROGINS com câncer de mama. Vários genes devem estar possivelmente relacionados com a etiopatogenia multifatorial do câncer de mama. O encontro destes, inclusive por meio de novas técnicas, como o microarray, nos permitirá, mais adiante, rastrear as mulheres com maior suscetibilidade para a doença e também avaliar e individualizar a melhor terapêutica clínica e, talvez, sua prevenção.

\section{Agradecimentos}

Fundação de Amparo à Pesquisa do Estado de São Paulo (FAPESP), projeto No. 04/0553-9.

\section{Referências}

1. Ministério da Saúde. Instituto Nacional do Câncer. Estimativa da incidência e mortalidade por câncer no Brasil. Rio de Janeiro: Secretaria Nacional de Assistência à Saúde; 2001. p. 8-9.

2. Leal CT, Santos KRRA, Nunesmaia HGS. Características epidemiológicas do câncer de mama no estado da Paraíba. Rev Bras Mastol. 2002; 12(2):15-22.

3. Da Fonte de Amorim L, Rossini A, Mendonça G, Lotsch P, de Almeida Simão T, de Moura Gallo C, et al. CYP1A1, GSTM1, and GSTT1 polymorphisms and breast cancer risk in Brazilian women. Cancer Lett. 2002;181(2):179-86.

4. Rossit A, Froes NDTC. Suscetibilidade genética, biometabolismo e câncer. Rev Soc Bras Cancer. 2000;3(10):26-31.

5. Wang-Gohrke S, Chang-Claude J, Becher H, Kieback DG, Runnebaum IB. Progesterone receptor gene polymorphism is associated with decreased risk for breast cancer by age 50. Cancer Res. 2000;60(9):234850 . 
6. Fabjani G, Tong D, Czerwenka K, Schuster E, Speiser $\mathrm{P}$, Leodolter $\mathrm{S}$, et al. Human progesterone receptor gene polymorphism PROGINS and risk for breast cancer in Austrian women. Breast Cancer Res Treat. 2002;72(2):131-7.

7. Donaldson CJ, Crapanzano JP, Watson JC, Levine EA, Batzer MA. PROGINS Alu insertion and human genomic diversity. Mutat Res. 2002;501(1-2):137-41.

8. Kieback DG, Tong XW, Weigel NL, Agoulnik IU. A genetic mutation in progesterone receptor (PROGINS) leads to an increased risk of non-familial breast and ovarian cancer causing inadequate control of estrogen receptor driven proliferation. J Soc Gynecol Investig. 1998;5(1 Suppl 1):40A.

9. De Vivo I, Hankinson SE, Colditz GA, Hunter DJ. A functional polymorphism in the progesterone receptor gene is associated with an increase in breast cancer risk. Cancer Res. 2003;63(17):5236-8.

10. Garret E, Rowe SM, Coughlan SJ, Horan R, McLinden $\mathrm{J}$, Carney DN, et al. Mendelian inheritance of a Taq I restriction fragment lenght polymorphism due to an insertion in the human progesterone receptor gene and its allelic imbalance in breast cancer. Cancer Res Ther Control. 1995;4(3):217-22.

11.Lancaster JM, Berchuck A, Carney ME, Wiseman R, Taylor JA. Progesterone receptor gene polymorphism and risk for breast and ovarian cancer. Br J Cancer. 1998;78(2):227.

12. Manolitsas TP, Englefield P, Eccles DM, Campbell IG. No association of a 306-bp insertion polymorphism in the progesterone receptor gene with ovarian and breast cancer. Br J Cancer. 1997;75(9):1398-9.
13. Wieser F, Scheneeberger C, Tong D, Tempfer C, Huber JC, Wenzl R. PROGINS receptor gene polymorphism is associated with endometriosis. Fertil Steril. 2002;77(2):309-12.

14. Graham JD, Yager ML, Hill HD, Byth Dagger K, O'neill Ddagger GM, Clarke CL. Altered progesterone receptor isoform expression remodels progestin responsiveness of breast cancer cells. Mol Endocrinol. 2005 Jun 23; [Epub ahead of print].

15. Aupperlee MD, Smith KT, Kariagina A, Haslam SZ. Progesterone receptor isoforms A and B: temporal and spatial differences in expression during murine mammary gland development. Endocrinology. 2005; 146(8):3577-88.

16. Carvalho CV, D’Amora P, Sato H, Girão MJBC, Lima GR, Silva IDCG, et al. Polimorfismo do gene do receptor da progesterona (PROGINS) em mulheres com endometriose pélvica. Rev Bras Ginecol Obstet. 2004;26(8):613-7.

17. De Vivo I, Huggins GS, Hankinson SE, Lescault PJ, Boezen M, Colditz GA, et al. A functional polymorphism in the promoter of the progesterone receptor gene associated with endometrial cancer risk. Proc Natl Acad Sci USA. 2002;99(19):12263-8.

18. Pearce CL, Hirschhorn JN, Wu AH, Burtt NP, Stram DO, Young S, et al. Clarifying the PROGINS allele association in ovarian and breast cancer risk: a haplotype-based analysis. J Natl Cancer Inst. 2005;97(1):51-9. 